\title{
Postural Control in Older Adults
}

Neil B. Alexander, $M D$

$\mathrm{M}$ aintaining balance is essential to carrying out daily tasks without falling. This review will describe the impact of impaired postural control on older adults, operationalize what is meant by postural control, and outline postural control test batteries. Findings from highly quantitative, laboratorybased studies will be discussed because these data serve as the foundation of knowledge regarding aging and postural control. Most of the review will be concerned with the changes in postural control that can be expected with aging and how aging and disease affect organ-system-based models of postural control. The review will also identify how age- and disease-related organ system changes might affect training to improve postural control.

\section{IMPACT OF IMPAIRED POSTURAL CONTROL}

Impaired postural control (defined more specifically below) will ultimately result in falls, ie, a fall is the result of inadequate functional balance. Falls and fallrelated injuries in older adults are common; nearly onethird over those aged 75 and over fall at least once and $6 \%$ sustain fractures over a 1 -year period. ${ }^{1}$ A major risk factor for falling in this prospective study is a high number of balance and gait abnormalities. It thus appears that older adult fallers are not able to maintain postural control as well as those who do not tend to fall. Fallers sway more in quiet or perturbed stance ${ }^{2,3}$ and differ in their responses to a backward waist pull. ${ }^{4}$ Fallers also have more difficulty than non-fallers in performing simulations of tasks and position changes required for daily activity, ie, simulations of activities of daily living. Fallers tend to be more unsteady in quiet stance, particularly with eyes closed and in response to a sternal push, more unsteady sitting down, more unsteady when asked to turn while walking, and less able to stand on one leg. ${ }^{5-8}$ In many studies, risk factors strongly associated with falls include lower extremity disability, often consisting of leg weakness, and sensory abnormalities such as impaired position sense. ${ }^{1,6,7,9}$ These risk factors involve organ systems that contribute directly to maintenance of postural control (see below).

Many older adults, not necessarily characterized as fallers, frequently admit to difficulty with balance or unsteadiness, particularly when changing positions or

From the Division of Geriatric Medicine, Department of Internal Medicine, the University of Michigan, and the Geriatric Research, Education, and Clinical Center, Ann Arbor VA Medical Center, Ann Arbor, Michigan.

This work was supported by an NIA Special Emphasis Research Career Award (SERCA) AG00519.

Address correspondence to Neil Alexander, MD, Division of Geriatric Medicine, 300 North Ingalls Building, Ann Arbor, MI 48109. while walking. Recent representative samples have found that more than $36 \%$ of those aged 75 complain of postural disturbances, most commonly unsteadiness. ${ }^{10}$ Although $13 \%$ of those aged 65 to 69 living in the community complain of balance difficulties while walking, $46 \%$ of those 85 years and over have the same complaint. ${ }^{11}$

\section{DEFINING BALANCE AND POSTURAL CONTROL}

Without external support, we balance ourselves in a potentially unstable equilibrium while muscular energy continually counteracts gravity. ${ }^{12} \mathrm{~A}$ more specific aspect of balance, postural control, can be defined as the maintenance of the body center of mass over its base of support or, more generally, within the limits of stability. ${ }^{12-14}$ These stability limits are operationally the area in which the center of mass can be moved safely without changing the base of support. When a person stands on a force plate, the center of vertical reaction force under the feet, known as the center of reaction or center of pressure (COP), can be estimated, and movements in COP then become indicators of stability. The stability limits vary according to: 1) the person's biomechanics, ie, body morphology and configuration, joint torque strength, speed at which the torque strengths can be developed, and joint range of motion; 2 ) the task requirements and any support for the body available; and 3) the support surface conditions, including angle, compliance, and friction. ${ }^{14,15} \mathrm{~A}$ person's perception of these limits (perceived stability limits) may differ from their actual stability limits and lead to an inappropriate postural response, such as may occur in patients with vestibular disorders. ${ }^{15}$

The ability to maintain postural control is critical for successful performance of nearly every daily task. This involves not just standing and walking, but tasks such as rising from a chair. ${ }^{16}$ Those who take more time to change positions, as indicated by the Get Up and Go Test, ${ }^{17}$ or who have difficulty in changing positions, as indicated by the Performance-Oriented Balance and Gait Assessment, ${ }^{18}$ tend to have more difficulty in formal quantitative balance tests. ${ }^{17,19}$ Having the ability to maintain various positions, to respond automatically to voluntary body and extremity movements, and to react to external disturbances represents the domains of postural control required in daily life. ${ }^{20}$ Yet, we often clinically test postural control only in a stationary, standing position, such as with the Romberg test. Screening tests such as the Performance-Oriented Balance and Gait Assessment ${ }^{18}$ and functional reach ${ }^{21}$ sample the universe of positions and situations in which postural control is needed. Although ambulation 
is an important part of this universe, a full discussion of gait-related postural control is beyond the scope of this review.

As body biomechanics, task requirements, and the support surface characteristics change, the appropriate postural response changes as well. Researchers often study postural responses evoked during at least four conditions, usually involving a sudden perturbation, or disturbance, of stance: 1) static (stationary), unperturbed stance (eg, standing quietly); 2) static perturbed stance (eg, standing on a platform that suddenly moves); 3) postural control during voluntary movement execution (eg, voluntary arm movement while standing); and 4) postural control during voluntary movement in the presence of a sudden perturbation (eg, altering treadmill speed while walking). ${ }^{22}$ Requirements to maintain postural control are often hierarchical, with one task presenting a greater challenge than another. For example, in older adults, unipedal stance is particularly more challenging than bipedal stance ${ }^{23}$ and standing on a slowly moving reduced-support surface (beam translation) is more challenging than standing on a slowly moving full-support surface (flat translation). ${ }^{24}$ Postural control responses, then, tend to be task- and perturbation-specific. ${ }^{22}$

\section{POSTURAL CONTROL TEST BATTERIES}

Test batteries that either have been used or may be useful in evaluating postural control in older adults appear in Table 1. The Clinical Test of Sensory Integration of Balance ${ }^{25,26}$ and Sensory Organization (SO) test $^{27,28}$ provide conflicts in the accuracy of visual and somatosensory information, presumably forcing the subject to rely on the vestibular system to resolve these sensory input conflicts. ${ }^{29}$ Some of these clinical tests use semiquantitative ratings of sway or balance strategies (Postural Stress Test ${ }^{4}$ Clinical Test of Sensory Integration of Balance, ${ }^{25,26}$ Performance-Oriented Balance Assessment ${ }^{18}$ ), whereas others use more quantitative timing, number of steps, or force plate (COP) information (Quantitative Ataxia Test, ${ }^{30}$ Dynamic Posturography ${ }^{27,28}$ ). Two scales (Balance Scale, ${ }^{20}$ Performance-Oriented Balance Assessment ${ }^{18}$ ) include items that represent positions or position changes encountered daily. Certain batteries may distinguish fallers from non-fallers and help identify those at risk for falls (Postural Stress Test, ${ }^{4,31}$ Performance-Oriented Balance Assessment ${ }^{18}$ ).

The semi-quantitative rating batteries can be used in a clinical setting are generally safe, take little time, are

TABLE 1. POSTURAL CONTROL TEST BATTERIES

\begin{tabular}{|c|c|c|c|}
\hline Test Name & Tasks Required & Outcome Variables & References \\
\hline $\begin{array}{l}\text { Quantitative Ataxia Test Bat- } \\
\text { tery }\end{array}$ & $\begin{array}{l}\text { EO, EC } \\
\text { Bipedal, Unipedal } \\
\text { Tandem stand/ } \\
\quad \text { walk } \pm \text { Rail }\end{array}$ & $\begin{array}{l}\text { Time } \\
\text { \# Steps on rail or in a straight } \\
\text { line }\end{array}$ & Graybiel $^{30}$ \\
\hline $\begin{array}{l}\text { Clinical Test of Sensory Inte- } \\
\text { gration of Balance } \\
\text { Postural Stress Test }\end{array}$ & $\begin{array}{l}\text { EO, EC, Dome } \\
\text { Flat, Foam } \\
\text { Resist waist pull of } \\
\text { different weights }\end{array}$ & $\begin{array}{l}\text { Time } \\
\text { Qualitative sway, Falls } \\
\text { \# trials without falls } \\
\text { Balance strategy score }\end{array}$ & $\begin{array}{l}\text { Shumway-Cook }{ }^{25} \\
\text { Anacker }^{26} \\
\text { Wolfson } \\
\text { Chandler }^{31}\end{array}$ \\
\hline $\begin{array}{l}\text { Performance-Oriented Balance } \\
\text { (and Gait) Assessment }\end{array}$ & $\begin{array}{l}\text { EO, Position } \\
\text { changes sit/ } \\
\text { stand, neck/ } \\
\text { back motion, } \\
\text { reach, bend, un- } \\
\text { ipedal stand }\end{array}$ & $\begin{array}{l}\text { Performance normal, adaptive } \\
\text { or abnormal }\end{array}$ & Tinetti $^{18}$ \\
\hline Balance Scale & $\begin{array}{l}\text { Position changes } \\
\text { sit/stand, stand } \\
\text { EO/EC, tandem } \\
\text { reach, turn }\end{array}$ & $\begin{array}{l}\text { 5-point scale based on ability } \\
\text { to perform task, time, dis- } \\
\text { tance }\end{array}$ & Berg $^{20}$ \\
\hline Dynamic Posturography & $\begin{array}{l}\text { Sensory Organiza- } \\
\text { tion (SO): EO, } \\
\text { EC, Sway ref. P } \\
\text { and V } \\
\text { Movement Coordi- } \\
\text { nation (MC): } \\
\text { Translations, ro- } \\
\text { tations }\end{array}$ & $\begin{array}{l}\text { Using Center of Pressure: } \\
\text { SO: Equilibrium strategy score } \\
\text { MC: Response latency, force, } \\
\text { strategy score, and bilateral } \\
\text { symmetry }\end{array}$ & $\begin{array}{l}\text { Ledin }^{27} \\
\text { Shepard }^{28}\end{array}$ \\
\hline
\end{tabular}

Eye conditions: $E O=$ eyes open; $E C=$ eyes closed; Dome $=$ modified paper lantern which moves in synchrony with head and designed to produce inaccurate visual orientation inputs (visual conflict).

Starting body configuration conditions: normally head and body erect, upright, and bipedal. Exceptions include unipedal stance and tandem stance (one foot in front of the other, heel to toe).

Support surface where feet are placed: Flat = firm, flat surface; Foam = piece of foam on top of flat surface; Rail = feet along longitudinal axis of rail 0.75 inch to 2.25 inch wide.

Support surface movement type: Stationary = no movement; Translation = platform moves anteriorly or posteriorly; Rotation $=$ platform rotates about the axis of the ankle (causing dorsi- or plantarflexion); Sway ref. $=$ sway referenced $=$ support platform $(P)$ or visual surround $(V)$ follows subject body sway.

Visual Push: illusory visual stimulus provided to standing subject to create sensation of self-movement and initiate corrective response. 


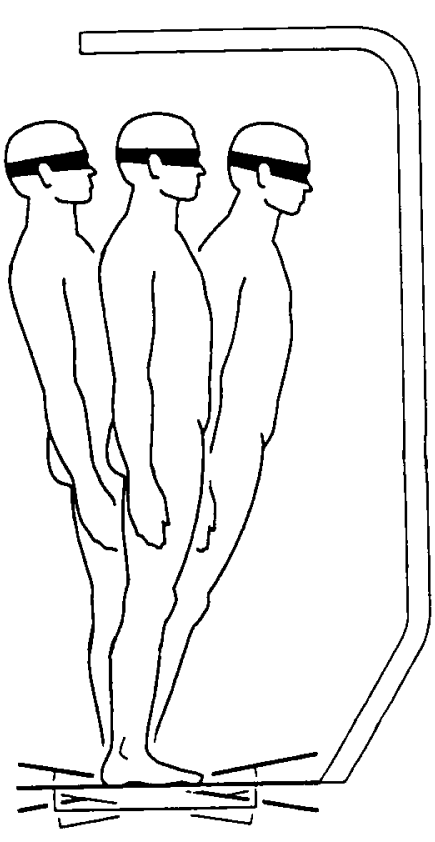

a

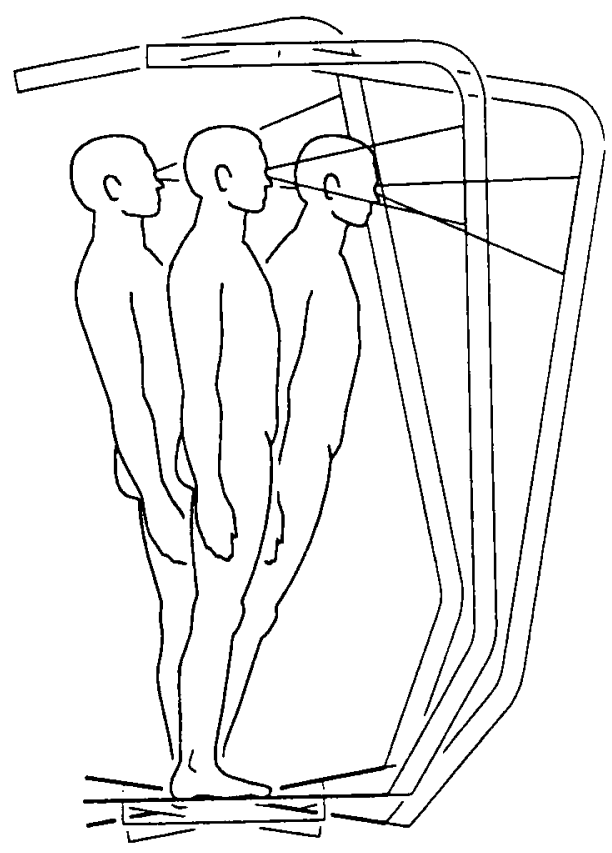

b
FIGURE 1. Two tests from the SO portion of dynamic posturography that appear to show age-related differences (see text): in a, vision is occluded and the platform is sway referenced (SO5 condition); in b, both vision and the platform are sway referenced (SO6 condition). Data acquisition focuses on reaction force changes under the feet. Each subject is suspended in a protective harness (not illustrated) to prevent a fall to the floor (based on Shepard et $\mathbf{a l}^{28}$ ). easy to administer, require little equipment, provide a semi-quantitative score, and have a certain degree of validity and reliability (which probably vary from item to item in each battery). As with many functional assessment instruments, the sensitivity of these batteries to change over time (such as during rehabilitation or functional decline) is somewhat unclear. Dynamic posturography is more quantitative but more complicated, expensive, and time consuming, and requires specialized equipment. Figure 1 shows two tests from the SO portion of dynamic posturography ${ }^{28}$ that appear to show age-related differences (see discussion below): in Figure 1a, vision is occluded and the platform is sway-referenced (SO5 condition) and in Figure 1b, both vision and the platform are sway-referenced (SO6 condition). Laboratory-based research-oriented tests tend to be even more complicated, but these tests are more controlled and quantitative.

Data from highly quantitative, laboratory-based tests serve as the basis for our knowledge regarding the effects of age and disease on postural control. Figure 2 shows an older adult's initial response to an anterior platform translation while standing on either a flat surface or a beam. ${ }^{24}$ Most data in this review are based on these types of studies. The laboratory-based studies have been criticized previously for lack of relevance in clinical settings. In a laboratory setting, to achieve adequate control and experimental validity, postural disturbances must be simplified and strict subject recruitment criteria observed. In the clinical setting, patients often present with multi-system impairments, and the complicated perturbations to which they are exposed daily result in complicated responses to maintain postural control. Nonetheless (as has been demonstrated with dynamic posturography), quantitative tests may be useful in patient care, such as in initial patient assessment and evaluation of treatment or ther-

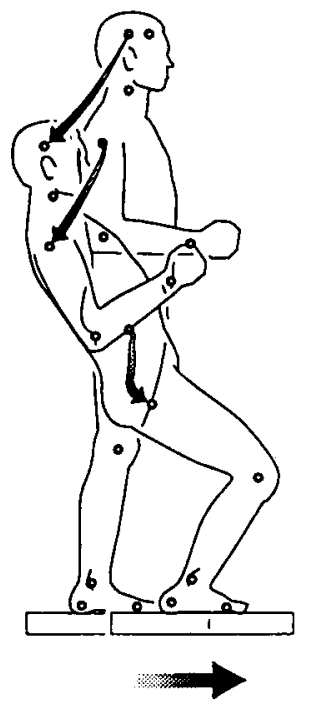

a

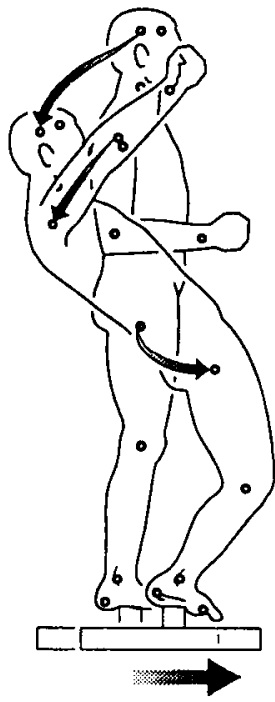

b
FIGURE 2. Older adult's initial response to an anterior platform translation while standing either on a flat surface (a) or a beam (b). Motion magnitude (gain) has been increased to illustrate typical body segment motion relationship patterns. Optoelectronic cameras (not illustrated) acquire body motion data via light-emitting diodes on key body landmarks. Arrows show movement of head, shoulder, and hip light-emitting diodes from start to maximum body segment excursion in posterior direction. Reaction force changes under the feet are also measured. Each subject is suspended in a protective harness (not illustrated) to prevent a fall to the floor (from data in Alexander et $\mathrm{al}^{24}$ ).

apy effectiveness. ${ }^{27,32,33}$ Moreover, laboratory-based measures, such as COP displacement and sway speed, show at least modest correlations ( $r$ approximately 0.4 to 0.6 ) with clinical measures of balance. ${ }^{19,34}$ Highly 
quantitative, laboratory-based postural control tests could be used eventually to predict future adverse events such as falls, particularly when changes in postural control are gradual and subtle. However, in the clinical setting, the incremental benefit of these quantitative data must be weighed against the expense and time commitment involved.

\section{CHANGES IN POSTURAL CONTROL WITH AGING}

It is difficult to establish age-related changes in postural control that are independent of disease. When young (usually 20 to 35 years old) and old (usually 65 years and over) adults with no apparent musculoskeletal or neurological impairment stand quietly or are subjected to mild disturbances of stance, age-related response differences in measured sway tend to be minimal. The differences between apparently healthy young and old adults for sway and step responses, body motion strategy scores, and timed stance are not substantial until tests of more severe perturbations of stance are administered (Table 2). Compared with young control subjects, healthy older adults who stand bipedally (eyes open or closed and on a firm, flat surface), even if subjected to a mild translation or backwards waist pull, do not differ substantially in their postural responses. Even if there is a statistically significant difference, the group differences are generally less than $30 \%$ and this translates into a difference, for example, of a few degrees of motion or millimeters of sway area. On the other hand, any increase in the severity of these perturbations may bring out more substantial young-old differences. ${ }^{23,24,28,31,35-48}$ The perturbations of increased severity include:

(1) Changing the support surface, such as use of a more compliant surface (foam), a reduced support surface area (beam) or an unstable surface (sway-referenced, ie, rotates according to subject's sway);

(2) changing the starting body configuration, such as standing unipedally, leaning forward, or extending the head backwards;

(3) altering the visual input, including occluding vision (either total or peripheral), moving the visual surrounding (such as sway-referenced, ie, rotates according to the subject's sway), or creating the illusion of self-movement ("visual push");

4) translating (moving horizontally) or rotating (moving vertically usually around axis of ankle) the support surface, or pulling backwards at the waist, particularly at increasing magnitude.

In addition to the perturbation type and severity, body configuration influences the difficulty involved in the task, as illustrated by the following examples. Unipedal stance is probably easier to perform when arms are outstretched, ${ }^{23}$ instead of folded on the chest. $^{30}$ Where the subject is in regards to his or her sway cycle (such as the amount of forward or backward lean) can influence the way a unidirectional sagittal perturbation, such as a waist pull or ankle rotation, affects the postural response. ${ }^{37,}$ In bipedal stance, the interfoot mediolateral or anteroposterior distance and the degree of foot toe-in or toe-out have different effects on postural sway. ${ }^{50}$

Some measures of sway may be better at revealing age-related differences than others. Using the COP at the feet, the area of sway excursion and the maximum peak-to-peak magnitude of sway excursion can be estimated. For a given perturbation, the maximum peak-to-peak COP excursion or the speed of COP excursions may differentiate young and old adult sway patterns better than the root-mean-square COP displacement (relative to the mean COP location). ${ }^{38}$ Timed measures of COP excursion such as COP excursion speed may be more useful in assessing age-related change because these measures estimate the frequency of postural corrections made. ${ }^{38,41}$ Power spectrum analyses, which measure the power (or energy) used at different motion frequencies, ${ }^{51,52}$ have not been applied fully in aging populations. These analyses may be advantageous in characterizing frequent rapid postural responses over an extended time period.

Young-old differences in studies using electromyographic (EMG) data ${ }^{39,43,48}$ are most striking in order or grouping of muscle activation patterns. In response to platform perturbations, the temporal sequencing of activation patterns are substantially altered, and contraction amplitudes are more variable in older adults, ${ }^{39,48}$ which may lead to inappropriate postural responses in certain circumstances. Young-old differences in time of muscle activation (latency), on the other hand, are small (for tibialis anterior, $101 \pm 12$ msec for young, $112 \pm 15 \mathrm{msec}$ for old in Manchester ${ }^{39}$ ). Compared with the stereotyped leg responses occurring during sway in young adults, older adult responses have more left- to -right asymmetry and have less inhibition of inappropriate responses. ${ }^{43}$ A concern has been raised recently regarding the use of EMG parameters in testing postural control in older adult fallers and non-fallers. In these groups and compared with studies done in young control subjects, ${ }^{53}$ many lower extremity EMG sequences are judged as uninterpretable (particularly due to tonic activity), asymmetric between the left and right sides, and not reproducible. $^{8}$

Underlying disease, as indicated by subtle neurological findings, ${ }^{39}$ may account for some of the young-old differences noted in postural control. Some studies show small but statistically significant age-related differences in bipedal, eyes-open stance, but the samples may have included subjects with varying levels of disease. $^{38,54-55}$ Nevertheless, the most striking age-related differences in these studies are in the unipedal, eyes-open stance ${ }^{54}$; bipedal, eyes-closed stance 55 ; and perturbed, eyes-open stance. ${ }^{38}$ Future postural control studies should carefully screen so-called "healthy" older adult subjects for subtle underlying disease that might influence study findings. Unfortunately, it is unclear whether one should exclude subjects who are minimally symptomatic from common musculoskeletal conditions (such as osteoarthritis) or who have neurological findings on examination that are common in older adults (such as reduced Achilles reflexes). Many of these older adults are otherwise active, get regular exercise, and perceive themselves as having no diffi- 
TABLE 2. STUDIES OF PERTURBED STANCE COMPARING APPARENTLY HEALTHY YOUNG AND OLD ADULTS

\begin{tabular}{ccccc}
\hline Study & Conditions/Perturbation & Outcome Variable & $\begin{array}{l}\text { Young/Old } \\
\text { Difference }\end{array}$ & Comments \\
\hline
\end{tabular}

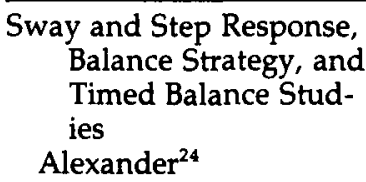

\author{
EC, Flat, Beam \\ Stationary/Transla- \\ tion
}

EO, EC

Bipedal, Unipedal

Backward Waist Pull, EO

$\mathrm{EO}, \mathrm{EC}$

Bipedal, Unipedal

EO, Forward lean

Backward Waist Pull, EO

EO

Stationary, translation

Sway response

Step response

30 s stance time

Sway response

Sway response

Sway and step responses

$\mathrm{EO}, 4$ direction lean Bipedal, Unipedal

EO, Visual Push

Flat, Foam

EO, EC

Flat, Foam

EO, EC

Stationary, translation Rotation \pm sway ref.

EO, EC, Head Ext. Flat, Foam

EO, EC

Flat, Foam

Transitions from EO to $\mathrm{EC}$ to $\mathrm{EO}$

$\mathrm{EO}, \mathrm{EC}$ Sway ref $\mathrm{P}$ and $\mathrm{V}$
Sway response

Extent lean

Sway response

Sway response

Sway response

Body motion strategy

Body motion onset

Sway response

Sway response

Sway response

Fall response
No/Yes Minimal differences in flat translation

Larger difference in beam stationary and beam translation.

No/Yes No difference in bipedal $\mathrm{EO} / \mathrm{EC}$.

Marked difference in Unipedal, esp. EC

No

No/Yes Small difference in bipedal EC.

Marked difference in Unipedal, esp. EC

Yes/No One sway variable shows difference, mostly in forward lean

No/Yes No difference at lower pull magnitudes

Difference increases at higher magnitudes

Yes/No Small differences in stationary and translation, but no difference in one standard measure (root mean square of COP displacement)

Yes/No Differences in extent lean, unipedal sway but no difference in bipedal sway

Yes/No Difference in either flat or foam for sway speed, but no difference for sway magnitude

Yes/No Small difference in all tests, no disproportionate increase with EC, foam

Yes Difference in translation, EC, P or V sway ref.

Larger difference in combination $P$ sway ref. with $\mathrm{EC}$, or P sway ref with V sway ref

Yes Differences small in EO Flat, highest differences in Foam/EC, Head Ext./EC

No/Yes No difference in flat/EO or EC

Difference in foam, esp. Foam/EC.

No/Yes No difference in sway range and variability

Difference in sway reduction during transitions

No/Yes Minimal sway difference until sway ref. P.

Highest $O$ fall response in sway ref $P$ plus EC

Table 2-continued 
TABLE 2-Continued

\begin{tabular}{|c|c|c|c|c|}
\hline Study & Conditions/Perturbation & Outcome Variable & $\begin{array}{l}\text { Young/Old } \\
\text { Difference }\end{array}$ & Comments \\
\hline \multicolumn{5}{|l|}{$\overline{\text { EMG Studies }}$} \\
\hline Stelmach $^{43}$ & $\begin{array}{l}\text { Translation } \\
\text { Voluntary Sway }\end{array}$ & $\begin{array}{l}\text { Sway response } \\
\text { Leg EMG onset, amplitude }\end{array}$ & Yes & $\begin{array}{l}\text { Old slower, less reliable, less } \\
\text { stereotyped, and less coor- } \\
\text { dinated muscle responses. }\end{array}$ \\
\hline Stelmach ${ }^{44}$ & $\begin{array}{l}\mathrm{EO}, \mathrm{EC} \\
\text { Rotations: slow } / \text { small, } \\
\quad \text { large/fast }\end{array}$ & $\begin{array}{l}\text { Sway response } \\
\text { Leg EMG amplitude, onset, } \\
\text { sequence }\end{array}$ & No/Yes & $\begin{array}{l}\text { No difference in fast, large } \\
\text { perturbations } \\
\text { Difference in slow, small } \\
\text { perturbations }\end{array}$ \\
\hline Manchester ${ }^{39}$ & $\begin{array}{l}\text { Translation } \\
\text { Rotation/sway ref. } \\
\text { Occlude periph. or fo- } \\
\text { veal, translucent, } \\
\text { EO, EC }\end{array}$ & $\begin{array}{l}\text { Sway/Fall response } \\
\text { Leg EMG amplitude, onset, } \\
\text { sequence }\end{array}$ & No/Yes & $\begin{array}{l}\text { No difference in EMG onset } \\
\text { (latency) } \\
\text { Leg muscle activation se- } \\
\text { quence altered in old } \\
\text { Old fall more in occlude } \\
\text { periph. and P sway ref. } \\
\text { More falls in subjects with } \\
\text { abnormal exam }\end{array}$ \\
\hline Woollacott ${ }^{48}$ & $\begin{array}{l}\text { Translation } \\
\text { Rotation }\end{array}$ & $\begin{array}{l}\text { Leg EMG amplitude, onset, } \\
\text { sequence }\end{array}$ & Yes & $\begin{array}{l}\text { Leg muscle activation se- } \\
\text { quence altered in old }\end{array}$ \\
\hline
\end{tabular}

Eye conditions: $E O=$ eyes open; $E C=$ eyes closed

Starting body configuration conditions: normally head and body erect, upright, and bipedal. Exceptions include head extension backwards (Head Ext.), unipedal stance, and leaning forward.

Support surface where feet are placed: Flat = firm, flat surface; Foam = piece of foam on top of flat surface; Beam = feet placed across $11 \mathrm{~cm}$ beam. Support surface movement type: Stationary = no movement; Translation = platform moves anteriorly or posteriorly; Rotation $=$ platform rotates about the axis of the ankle (causing dorsi- or plantarflexion); Sway ref. = sway referenced $=$ support platform (P) or visual surround $(V)$ follows body sway.

Visual Push: illusory visual stimulus provided to standing subject to create sensation of self-movement and initiate corrective response. Vision altered by special goggles: periph. = peripheral occluded, foveal (central) vision available; foveal = foveal occluded, peripheral vision available; translucent $=$ translucent goggles altering visual feedback.

All sway is a passive response to perturbation, except for voluntary sway, where subject actively begins sway.

culty with mobility. The use of a highly selective, screened older adult sample for these studies might overestimate the postural control abilities of other "less healthy" older adults living independently in the community. ${ }^{44}$

In response to repeated slow-speed, small-amplitude platform rotations, old adults have an increasingly larger range of sway ( $32 \mathrm{~mm}$ to $36 \mathrm{~mm}$ ) as the number of perturbations increases, compared with young adults, who have a decreasingly smaller range $(24 \mathrm{~mm}$ to $21 \mathrm{~mm}){ }^{44}$ Paradoxically, there are no age differences in response to repeated fast-speed, large-amplitude rotations. The authors conclude that whereas the fastlarge perturbation requires fast postural responses still available in the healthy older adults, the slow-small perturbation requires slower responding central integrative processes. These higher central level processes may decline in older adults (see below for discussion on central function). Thus, increased exposure time to a postural disturbance can bring out age-related changes. This may explain why young and old body motions are more consistently different when standing on a stationary beam for 10 seconds as compared with responding to a rapid translation while standing on a beam for 2 seconds. ${ }^{24}$

Postural control also probably declines into advanced old age, such as age 80 or older. As age increases from age 60 to 80 and over, sharpened Romberg (standing heel to toe) and unipedal stance times are reduced. ${ }^{56}$ Sway velocity increases as well into ad- vanced old age, ${ }^{55}$ although, as above, the presence of subtle disease may confound age effects.

\section{SYSTEMS INVOLVED IN MAINTENANCE OF POSTURAL CONTROL}

\section{Organ System Models}

One of the prototypic models for postural control proposes that multi-synaptic stereotyped "long-loop" reflexes guide postural responses to unexpected rapid perturbations. 57 During unexpected flat-surface translations, responses in young normal subjects begin with activation at the ankle and proceed proximally on the same ventral or dorsal aspect into the trunk; this is known as the ankle strategy. ${ }^{58,59}$ Responses to translation while standing on a support surface shortened in relation to foot length (beam) activate at the trunk and thigh and proceed distally; this is the hip strategy. ${ }^{58}$ However, pure ankle or hip strategy sequences are not always seen in each subject or in each test trial. During transitions between a flat and beam surface, neither strategy is present in pure form but, instead, may occur as complex combinations of both ankle and hip strategies. The data in these studies may be influenced by the "locked" knee starting configurations, which could limit the muscle activation options, ${ }^{59}$ and by the use of practice trials to achieve consistent performance. ${ }^{58}$

In subsequent studies, the neck, back, and abdominal muscles may activate as early as the ankle muscles in 
response to a platform translation. ${ }^{60}$ Moreover, after sudden ankle dorsiflexion, coordinated activity of the ankle and neck correct body sway and stabilize the head, respectively; this response is presumably derived from the vestibulospinal system ${ }^{61}$ and is augmented by the lower leg spindle afferents. ${ }^{52,62}$ Thus, another model proposes that a more centralized system, which receives visual, vestibular, and neck and ankle proprioceptive input, serves to guide responses to a postural disturbance. ${ }^{63}$ Both central and peripheral mechanisms are probably involved in producing the stereotyped postural responses reported previously. ${ }^{64}$ Perhaps rapid postural corrections are the result of reflex-like responses not immediately modified by the visual or vestibular system, while responses to slower or continuous displacements require visual, vestibular, and somatosensory feedback and may be more subject to modification. ${ }^{65}$

These more comprehensive models focus on the integrative aspects of the central and peripheral nervous systems, with the vestibular system ${ }^{66}$ and the cerebellum $^{67}$ serving as the primary mediators of control. In the model proposed by Keshner ${ }^{66}$ shown in Figure 3, multiple neural structures are involved in the behaviors initiated by vestibular stimulation. Vestibular input can be generated through head and body movements, descending signals from higher centers, and, although not pictured, visual and somatosensory afferents. The cerebellum is thought to modify limb and trunk movements initiated by the vestibulospinal tract. $^{66,68}$ Without cerebellar input, opposing muscle forces are not balanced, and the postural response is not graded over the appropriate time to optimize muscle coactivation to the demands of the task. ${ }^{67,69}$

Other models also consider the musculoskeletal system as critical in postural responses. ${ }^{15}$ This is especially important in older adults because of the decline in strength with age, particularly in the lower extremities. $^{70}$

In a model of postural control specifically in older

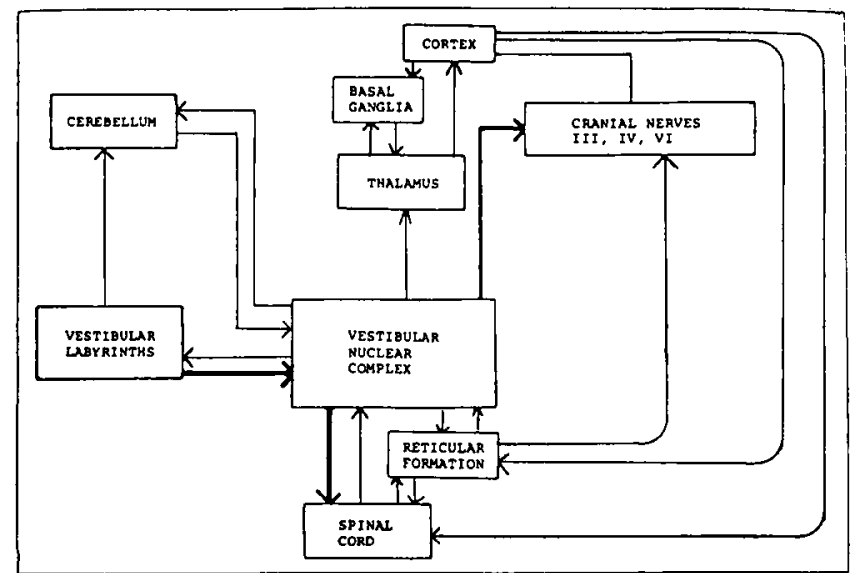

FIGURE 3. Multiple neural structures involved in the behaviors initiated by vestibular stimulation. Vestibular input can be generated through head and body movements, descending signals from higher centers, and, although not pictured, visual and somatosensory afferents. Reprinted from Keshner and Cohen ${ }^{66}$ with permission of the publisher. adults, peripheral sensation (ie, touch sensitivity and proprioception) contributes the most to maintenance of postural stability, followed by visual and vestibular function. ${ }^{71}$ However, most of the variance in this postural control model is left unexplained. Important components, such as central integrative factors, may not be accounted for in the model. Other models of mobility in older adults include "centrally" related capabilities that contribute to maintenance of postural control, such as problem-solving ability, motivation, and attention. ${ }^{18}$

\section{Impact of Aging Versus Disease on Organ System Function and on Maintenance of Postural Control}

Age-related morphologic (and functional) changes are seen particularly in striated muscle, peripheral nerves, peripheral receptors, the dorsal columns, the cerebellum, and the cerebral cortex. ${ }^{72-74}$ How all of these changes impact directly on postural control is unclear. Nonetheless, age-related changes in visual, vestibular, somatosensory, musculoskeletal, and higher cortical or central function, as discussed below, affect maintenance of postural control in older adults.

Visual System Decrements in visual acuity, depth perception, contrast sensitivity, and perception of the true vertical or horizontal are associated with falls, fallers, and hip fractures ${ }^{1,75-78}$ but not consistently in every study. ${ }^{6,9,79}$ These decrements in visual function are not necessarily just age related, but generally reflect the effects of underlying diseases as well. ${ }^{78}$

Visual cues are thought to be useful in maintaining postural control, in both slow body (particularly upper extremity) reorientation after a displacement and rapid stabilization of the body working upward from the feet. ${ }^{80}$ Unexpected alterations in visual input, such as those created by moving the visual frame of reference, also cause changes in postural response. ${ }^{81}$

Changes in spatial frequency sensitivity, visual acuity (particularly in the periphery), sensitivity to glare, dark adaptation, stereopsis, and contrast sensitivity are found with age. ${ }^{82-84}$ The effect of altered visual function, such as contrast sensitivity, on postural control may be most striking in the ability to detect and discriminate obstacles in the environment. ${ }^{85}$ Decreased contrast sensitivity and decreased visual acuity in older adults are associated with increased sway on a foam support surface. ${ }^{75}$ Postural sway increases when older adults are subjected to horizontally oriented visual cues or limited visual acuity. ${ }^{86}$ Older adults are more likely than young adults to fall during balance testing when peripheral vision is experimentally occluded and only foveal vision is available. ${ }^{39}$

In summary, age- and disease-related decrements in visual function place older adults at risk for falls and altered postural responses. Because postural responses in older adults can be altered by experimentally modifying visual input, there are likely to be vision-related circumstances where an older adult is at increased risk for impaired postural control and falls.

Somatosensory System Somatosensory abnormalities, such as impaired position sense or touch sensitivity, are associated with falls and postural instabil- 
ity. ${ }^{6,9,71}$ Somatosensory influences on postural control, specifically in the lower extremity, are thought to be mediated through changes in muscle spindle activity, joint receptor activity (which may come into play only at the extremes of angular displacement), and cutaneous receptors, particularly in the sole of the foot. ${ }^{87}$

Proprioception in the knee and metatarsophalangeal joint, as measured by the accuracy of repositioning or by the ability to determine threshold of motion, may decline with age. ${ }^{88,89}$ Yet these changes may depend on the frequency of motion used for threshold determination, ${ }^{88}$ and may also depend on the type of analyses used, as there may be no age difference in analyses by semi-decades ${ }^{88}$ and because a subgroup of older adults may have performed more poorly than the rest. ${ }^{89}$ Touch sensitivity, as measured by tactile threshold, declines minimally with age, and there is evidence that a subgroup over age 60 had no change in threshold. ${ }^{90}$

Somatosensory loss, either induced experimentally or caused by disease, alters postural responses in certain situations. Normal subjects who are subjected to an ischemic block above the ankles maintain their postural EMG response to ankle rotation perturbations and exhibit sway at certain frequencies, such as 1 $\mathrm{Hz}^{51,52}$ These $1-\mathrm{Hz}$ responses are similar in subjects with tabes dorsalis who have lost proprioceptive input in the lower extremities. ${ }^{51,91}$ Finally, in responding to a postural disturbance, normal subjects who have their feet hypothermically anesthetized will sway more and are slower to adapt to the disturbance. ${ }^{92}$ In older adults, altered somatosensory input is thought to be associated with a higher rate of falls or increased sway while standing with eyes closed either on foam $^{46}$ or on a sway-referenced platform. ${ }^{39,48}$

Thus, as with vision, decrements in somatosensory function place older adults at risk for falls and altered postural responses. Although age-related changes in proprioception may not be clinically significant, disease-related somatosensory changes and certain support surfaces might place an older adult at increased risk for impaired postural control and falls.

Vestibular System The contribution of vestibular dysfunction to falls in older adults is not clear from epidemiological studies. This may be due to the more complicated testing required to demonstrate even subthe vestibular dysfunction.

Age-related anatomic changes in vestibular organs, such as a reduction in the number of hair cells in the maculae and cristae ${ }^{93}$ are not necessarily accompanied by changes of equal magnitude in vestibular function, as evidenced by vestibulo-ocular reflex (VOR) testing. ${ }^{94}$ Thus, VOR function is better in older adults than might be predicted based on vestibular anatomic changes; this might suggest that central nervous system adaptive mechanisms are important in maintaining the VOR in older adults. ${ }^{94}$

Few studies have examined the relationship between vestibular function and postural control in older adults. Patients aged 18 to 85 with unilateral peripheral vestibular loss have difficulty initially with sway-referenced visual and platform conditions (sensory conflict conditions) on dynamic posturography. ${ }^{33}$ In the longer post-operative intervals in which the VOR no longer improves, posturography continues to improve. This suggests that physiological measures do not correspond perfectly with functional measures, and that compensatory adaptive changes continue. Of note, the residual abnormalities found on dynamic posturography in these vestibular patients are in SO5 and SO6, (swayreferenced platform with eyes closed or sway-referenced vision), and are the same conditions found to be abnormal in older adults who would otherwise not appear to have a vestibulopathy. ${ }^{28}$

One of the roles of the vestibular system is to stabilize the head. ${ }^{95}$ Healthy older adults may not be able to stabilize the head as well as young adults in response to postural disturbances. ${ }^{24}$ Because head and neck inertial and visco-elastic forces (eg, stiffness) are important in head stabilization, ${ }^{96}$ older adults, particularly those with cervical osteoarthritis, may have different mechanical forces operating than young adults. Although it has been suggested that cervical spine mechanoreceptors (such as at the apophyseal joints) contribute to declines in postural stability with age, ${ }^{97}$ muscle spindles and Golgi tendon organs in large dorsal neck and perivertebral muscles may make greater contributions to ascertaining joint position. ${ }^{98}$

When extending the head backwards (such as at a $45^{\circ}$ tilt) with eyes closed, postural sway increases, ${ }^{86}$ disproportionately in older versus younger adults. ${ }^{45}$ Extending the head backward causes a change in vestibular organ orientation and thus alters vestibular feedback for maintaining posture, ${ }^{99}$ but it may also activate stretch receptors in the neck. ${ }^{100}$ Similarly, in patients with unilateral vestibular loss, tilting the head away from the side of the lesion increases postural sway, particularly in conditions in which the platform is sway referenced. ${ }^{101}$ These findings are thought to be due to central compensation mechanisms as well as altered neck stretch receptor activity. ${ }^{101}$

In conclusion, vestibular dysfunction, particularly as a result of aging, does not appear as a prominent factor for falls. However, to the extent that certain situations destabilize the head or place the head in an unfavorable position, vestibular processes, in connection with neck and cortical/central mechanisms, appear to be important for maintenance of postural control in older adults.

Integration of the Visual, Vestibular, and Somatosensory Systems The integration of the visual, vestibular, and somatosensory systems implies that alteration in one system increases the dependence on another system. Thus, the increased sway in older adults with head extension and eyes closed, causing altered vestibular and visual input, might suggest difficulty in relying on somatosensory input. ${ }^{45,86}$ Older adults may be less able to rely on vestibular function than younger adults because postural control is impaired in older adults when leg somatosensory and visual input are altered. ${ }^{39,46,48}$ The vestibular system provides an internal orientation reference that is critical in the resolution of conflict between sensory stimuli and may also generate postural responses. ${ }^{6,102}$ Vision can be initially dominant in determining sway control, particularly during sensory conflict, although changing 
environmental conditions may cause somatosensory input to dominate. ${ }^{103}$ Researchers are not in complete agreement on the extent or hierarchy of influence of visual, proprioceptive, and vestibular input on responses to whole body destabilization. ${ }^{66}$

Musculoskeletal System Lower extremity muscle weakness is a prominent risk factor for falls, particularly for frail or institutionalized ${ }^{6,9}$ but not consistently for community-dwelling ${ }^{79}$ older adults. Peak muscle torque and power are substantially reduced at the knee and ankle in fallers versus non-fallers. ${ }^{104}$

A decline in strength with aging, as measured by isometric or isokinetic torque is well established, particularly in the lower extremities. ${ }^{70,105}$ In addition to torque losses, power and work output decrease approximately $6 \%$ per decade in a sample aged 15 to 71 years $^{106}$; the age effect may be confounded by changes in older adult anthropometry (ie, decreased thigh volume). In frail older adults, leg extensor power is an important predictor of performance speed in such functional tasks such as walking, climbing stairs, and rising from a chair. ${ }^{107}$ Age-related changes in the time taken to produce a certain level of force may also be relevant to older adult postural responses. When extending the leg as rapidly as possible, healthy older adults are slower than young adults in reaching both their maximum level of isometric force and the equivalent percent of maximum isometric force. ${ }^{108}$ These reductions in both power and muscle explosive force capacity with age might influence postural responses in older adults, particularly responses to sudden, severe perturbations.

An age-related decrease in active joint range of motion and increase in stiffness (passive resistance to movement) in the lower extremity aggravate the problem of strength loss. ${ }^{105,109}$ Thus, in response to a postural disturbance, there is less strength available to move a stiffer joint through a more limited range of motion.

Nevertheless, the exact mechanisms of how declining strength and joint function relate to impaired postural control remain to be clearly defined. In fact, biomechanical analyses in healthy older adults show that the ranges of joint motions used and the joint torque strengths developed in response to perturbed stance are modest and well within the voluntary joint ranges of motion (ROM) and strengths available ${ }^{24}$ (and Ashton-Miller, et al, manuscript submitted). Thus, for healthy older adults, the influence of joint ROM and strength output on postural control appears minimal. For frail older adults, whose joint ROM and strength fall below the modest required threshold, joint ROM and strength may become an important factor in maintaining postural control. This relationship between strength and functional performance is likely curvilinear, as illustrated by Figure $4 .{ }^{11}$ Below a threshold of minimum strength, functional impairment (in the present case, postural instability or falls) is more likely. Above the threshold, strength is sufficient and in excess of the requirement for unimpaired function (maintenance of postural stability). As implied by the figure, the gradient of the curve changes with the task; unipedal stance for 60 seconds probably requires a higher

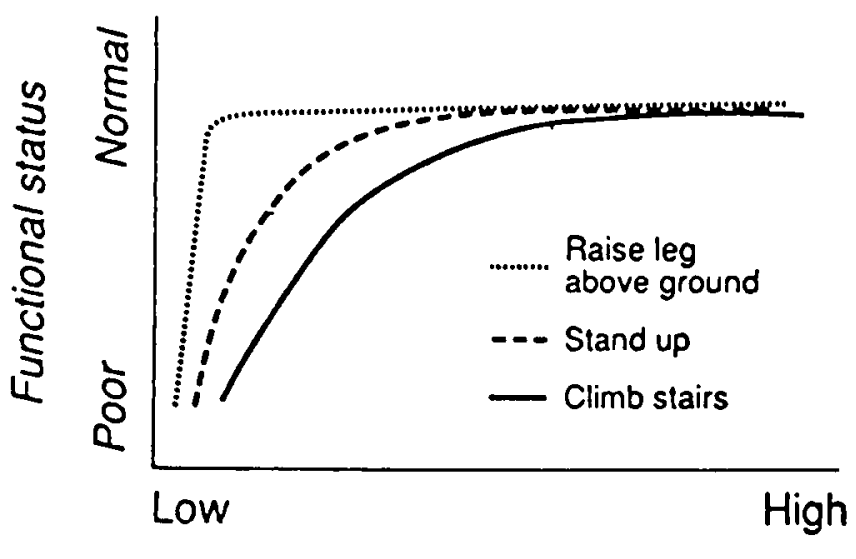

\section{Relative strength}

FIGURE 4. Curvilinear relationship of muscle strength to functional performance. Below a threshold of minimum strength, functional impairment (in the present case, postural instability or falls) is more likely. Above the threshold, strength is sufficient and likely in excess of what is required for unimpaired function (maintenance of postural stability). Reprinted from Buchner and deLateur ${ }^{111}$ with permission of the publisher.

strength threshold than bipedal stance, and increased strength will improve unipedal stance performance ${ }^{112}$ up to a different asymptotic level. Data from Bassey et $\mathrm{al}^{107}$ support this view, in that performance speed not only rises less steeply having reached a minimum leg extensor power level, but also tends to plateau.

Higher Cortical/Central System Cognitive impairment is associated with falls, ${ }^{1}$ yet the importance of higher cortical/central factors has been underemphasized in its potential influence on postural control. These factors often manifest themselves in a number of cognitive, behavioral, and affective domains.

With aging, performance of tasks requiring central nervous system processing are slowed, and there is particular slowing in information integration and/or response preparation processes. ${ }^{113}$ Slowing of motor skills is likely to occur at decision points; the new movement itself is not as slowed as much as the time to redirect movements in response to new information. ${ }^{114}$ Slowing of choice reaction time with aging may be related to the loss of precise control over the speed at which responses can be made, or to the loss of fine differentiation between 'fast' and 'slow' responses. ${ }^{115}$ Older adults may thus make more errors when they inadvertently move faster than their ability to move accurately. They subsequently correct these errors too slowly. Unfortunately, both speed and accuracy are required for postural responses. ${ }^{116}$ As the corrective postural response is delayed, the older adult is at increasing disadvantage to maintain control, for he or she has now presumably moved further from a stable upright posture. ${ }^{116}$ Age-related changes in central processing also affect lower extremity motions, which are directly related to maintenance of stance. Age-related slowing of the premotor time (the time between the stimulus onset and muscle activity onset) occurs in ankle dorsiflexion, hip extension, and knee extension $^{117}$ (and Ashton-Miller et al, manuscript submitted). In these two studies, compared with motor 
time (total reaction time minus premotor time), premotor time appears to make a more substantial contribution to prolonged reaction time in older adults. When there are multiple joints involved and multiple movement options, age-related slowing in central processing may influence substantially responses to a postural perturbation.

In addition to central processing speed cautiousness and risk avoidance, anxiety, lack of confidence, and fear of falling may also influence postural control. Cautiousness and risk avoidance are thought to be generally increased in older adults, ${ }^{119}$ although the risktaking judgments based on role-playing in these studies may not translate directly into risk-taking behavior. ${ }^{120}$ Experimentally induced stress or anxiety can increase postural sway in healthy young adults. ${ }^{121}$ In patients who admit to dizziness or imbalance, self-rated confidence in everyday mobility task performance is strongly associated with better postural test performance, whereas increased fear and anxiety are associated with poorer performance. ${ }^{122}$ Anxiety, via increased arousal, can reactivate the effects of a vestibular lesion for which compensation had already occurred. ${ }^{123}$ On the other hand, lack of attention and sedation are thought to decrease the vestibular response (see discussion on medications below).

Fear of falling can be operationalized by a test of low self-perceived efficacy (low confidence) in performance of daily tasks, the Falls Efficacy Scale. ${ }^{124}$ Increased fear of falling (higher Falls Efficacy Scale score) in older adults is associated with increased anxiety, difficulty in getting up from a fall in the past, and slowed walking pace. Poorer postural performance has been found in those who are fearful of falling. ${ }^{125}$ The implication is that fear of falling can result from an adverse past experience, particularly in those who have a certain personality trait (anxiety). Fear of falling may then ultimately lead to altered mobility and postural control. Fear of falling may also explain why some older adults, particularly those who are disabled, exhibit: 1) self-imposed restrictions or less effort compared with young adults in performing a challenging mobility task such as unipedal stance testing; 2) a "stiffened" reaction to a postural perturbation, as suggested by co-contraction of muscle agonists and antagonists; and 3) high tonic EMG activity during perturbation testing. $8,23,39,125$

Additional evidence for higher cortical/central involvement comes from postural control studies where the findings cannot be explained on the basis of the standard paradigm of visual, somatosensory, and vestibular system function. The asynchrony, asymmetry, and incoordination of postural responses in older as compared with younger adults, particularly when associated with voluntary movements, suggest problems with the hierarchical organization of movements with advancing age, ie, a higher cortical influence. ${ }^{43}$ Thus, an older adult might not be able to produce postural responses reliably, and this might partly explain why an older adult may move more conservatively, with less range of voluntary movement. ${ }^{43}$

Prior expectations, practice, and learning effects in postural testing provide additional evidence of higher cortical involvement. While being suspended in a parachute harness over a force platform, voluntarily controlling the initiation of a short vertical drop, as opposed to an unexpected initiation of the drop, reduces early, so-called "startle" EMG responses. ${ }^{126}$ Prior experience on a flat surface influences postural responses on a reduced support surface. ${ }^{58}$ After repeated platform translations, neck and ankle EMG activation and head motions are modulated, suggesting that subjects are able to relax and allow the lower body segments to absorb the impact of the displacement. ${ }^{127}$ Even in stroke patients, well-practiced, predictable voluntary weight shifts on a stable support can be performed as quickly in a paretic limb as in the contralateral normal limb. ${ }^{128}$

The activation of lower extremity or trunk postural muscles in anticipation of a focal voluntary movement, such as moving the arm rapidly while standing, also suggests a higher cortical/central influence. This activation appears to be specific to the particular state of postural equilibrium, the postural "set," organized from a central source. ${ }^{129}$ In arm movement while standing, leg and trunk postural muscles are often activated before arm muscle contraction and displacement, suggesting that the postural muscle response is centrally generated. ${ }^{130}$ These postural responses tend to be more slowly activated in association with arm movement in old as compared with young adults. ${ }^{131,132}$ This delay in postural muscle activation, ie, delayed stabilization, may have accounted directly for the delay in arm movement in older versus young adults. ${ }^{132}$ Other studies find anticipatory postural adjustments to be altered in older adults, independent of arm movement speed. ${ }^{133}$ Some researchers find no correlation between age and postural muscle activation associated with voluntary movement. ${ }^{130}$ The age difference in various studies may reflect the different mechanical requirements of the task, eg, task performance in a sitting versus standing position, ${ }^{134}$ which leads to different neural control strategies. ${ }^{131}$

Other evidence suggests that healthy older adults have more difficulty than young in reconfiguring an unexpected change in a postural set. Postural sway increases disproportionately in old compared with young adults when making transitions between eyes closed and eyes opened test conditions. ${ }^{47}$ In general, difficulty in reconfiguring a postural set can lead to errors in response (ie, impaired postural control) when the stimulus or external conditions change unexpectedly. ${ }^{135}$

The influence of distraction, or the performance of a cognitive task while trying simultaneously to maintain steady stance, is greater in subjects with impaired postural control (such as in lower limb amputees) versus control subjects. ${ }^{136}$ The implication is that complex, attention-demanding environments are liable to stress postural control, particularly in those who have preexisting impaired postural control.

Vestibular function can be modified by higher cortical/central, ie, voluntary influences. ${ }^{137}$ In patients with uncompensated peripheral vestibular lesions, postural response magnitudes to repeated stimuli decrease over time, indicating evidence for central habituation. ${ }^{69}$ 
Habituation is one of three mechanisms proposed to account for the ability to compensate for vestibular lesions: 1) central sensory substitution (ie, the increased reliance on visual and somatosensory information as opposed to vestibular input), 2) rebalancing tonic activity (ie, recovery of symmetric tonic activity in bilateral vestibular nuclei), and 3) physiologic habituation (ie, the decrease in response magnitude to repetitive sensory stimulation ${ }^{15}$ ). Note that the capacity for compensation to vestibular lesions is decreased with additional lesions in the cerebrum, cerebellum, brain stem, spinal cord, and sensory systems, ${ }^{15}$ suggesting the importance of an intact central system for successful compensation. ${ }^{68}$ Moreover, compensation can be retarded or decompensation induced by some medications (barbiturates, diazepam, chlorpromazine, certain anticholinesterases), or it may be facilitated by other medications (caffeine, amphetamines, anticholinergics such as atropine and scopolamine). ${ }^{138}$ The involvement of the cholinergic system in vestibular compensation is of particular interest because of the apparent involvement of the cholinergic system in Alzheimer's disease and the risk of drug-induced confusion with anticholinergic treatment in older adults. The impact of medications on postural control is discussed further below.

Thus, there appear to be many ways that higher cortical/central function, through alterations in cognitive and integrative processes and specific affective and behavioral factors, can influence postural control.

\section{POSSIBLE INFLUENCES OF SPECIFIC DISEASES OR MEDICATIONS ON POSTURAL CONTROL}

Postural responses seen in disabled older adults may reflect the influence of specific diseases or medications. In patients with peripheral vestibular disorders, even in those who have compensated for their loss, postural control is impaired in at least two situations: 1) where trunk and hip motion is required to maintain postural control; and 2) where no reliable visual or somatosensory information is available and only vestibular information is available. ${ }^{29}$

Patients with hemiplegia secondary to a cerebrovascular accident when compared with either young or age-matched control subjects, have altered postural control. First, their EMG responses to a perturbation have substantial variability, co-contraction of synergists, asynchrony, and distorted activation sequences. ${ }^{139-140}$ Second, when moving toward the paretic extremity, voluntary sway is slowed and more likely to be directed in planes of motion other than in the intended direction. ${ }^{141}$ Third, weight distribution at the feet is displaced more laterally. ${ }^{142}$ These hemiplegic cerebrovascular accident patients apparently not only have deficits in producing ordered, coordinated contractions, but they also may be less able to monitor sensory and proprioceptive feedback. ${ }^{128}$

Patients with Parkinson's disease generally respond to postural perturbations with normal EMG latencies but the strategy (ie, the amplitude, duration, and order of the EMG responses) may be inappropriate. ${ }^{143}$ Disordered EMG strategies result in "stiffness" in postural response and inappropriate strategies, ${ }^{144}$ as is evidenced by slowed angular rotation of the ankle despite equivalent leg EMG amplitude. ${ }^{145}$ Anticipatory postural responses in the legs of Parkinson's patients (before voluntary arm movement) are less frequent, of shorter duration, and are characterized by multiple EMG bursts. ${ }^{146}$ These anticipatory responses are absent or greatly reduced in Parkinson's patients who are identified as fallers or as having poor postural control. ${ }^{147}$

Patients with cerebellar disorders have increased sway in quiet stance, over-respond to perturbations by overshooting their sway reaction, and appear to have difficulty in coordinating the timing and amplitude of postural responses. ${ }^{67,143}$

Compared with age-matched control subjects, lower limb amputees have increased sway and may be more dependent on vision for maintaining postural control. ${ }^{148,149}$ As rehabilitation progresses with the prosthesis, both postural sway and the dependence on vision decreases, suggesting improved central integration of sensory input from the amputated limb. ${ }^{150}$

Diseases or medications causing orthostatic hypotension are linked to falls ${ }^{6}$ and possibly to increased postural sway. ${ }^{151}$ When comparing institutionalized older adults to young adults, position changes associated with common daily activities elicit more variable (and more striking declines in) blood pressures. ${ }^{152}$ Thus, orthostatic blood pressure changes and their associated risk of falls present another stressor for postural control during daily position changes in older adults. Medications, particularly psychotropics, are known to induce sway, ${ }^{153}$ perhaps by inducing sedation, confusion, and inattention, thereby influencing postural control via the central mechanisms discussed above.

\section{IMPLICATIONS FOR POSTURAL CONTROL TRAINING}

\section{Training and Exercise Program Outcomes}

Training programs in older adults have, thus far, not achieved consistently striking gains in the ability to maintain postural control, as reviewed by Buchner et al. ${ }^{154}$ Many of these studies have a small number of participants and may have difficulty in recruitment, in establishing equivalent groups at randomization, in compliance to the training program, and ultimately in statistical power. The results also may be a function of the health and fitness of the participants, the type of exercise utilized, the type and variability of outcome measures used, and how proficient participants were in baseline tasks. ${ }^{144,155}$ For example, an aerobic program may markedly improve the ability of relatively sedentary older women to change position rapidly (62\% improvement in number of sit-to-stands performed). However, the time to maintain single stance may improve only modestly ( $12 \%$ improvement) with the aerobic program, possibly because of a ceiling effect in the duration of single stance time used as an outcome measure. ${ }^{156}$ Baseline measures such as bipedal sway may already be at minimum level before exercise and have such low variability that no change with training can be demonstrated. ${ }^{157}$ Improvement may be seen 
only in tasks that older subjects tend to perform with moderate success at baseline (such as unipedal stance time, eyes open) as opposed to tasks with which even healthy older adults tend to have little success (such as unipedal stance time, eyes closed). ${ }^{158}$ Perhaps future multi-center trials will shed more light on the effectiveness of balance training.

\section{Strength and Muscle Response Training}

Strength training, of any type, in frail or sedentary older adults, will likely improve certain aspects of postural control, such as the ability to tandem walk. ${ }^{159}$ This training, particularly in the first few weeks, involves a neuromuscular component, as suggested by an accompanying increased EMG activation. ${ }^{160}$ The neuromuscular component may contribute more to strength increases for older than younger adults. ${ }^{161}$ Maximum integrated EMG output increases rapidly during early conditioning, and may increase less rapidly during later training, when muscle hypertrophy becomes a more dominant predictor of strength. ${ }^{160,162,163}$ Because limb immobilization is known to decrease integrated EMG magnitude, ${ }^{162}$ perhaps some of the striking changes in EMG output are due to reversal of the immobilization, ie, training. Fiatarone et $\mathrm{al}^{159}$ proposed that at least a portion of the strength gains in her relatively debilitated and immobile institutionalized cohort were likely to have occurred as a result of improved neural recruitment patterns. This is evidenced by the lack of correlation between the degree of muscle hypertrophy and relative strength gain, and by the strength gains which occurred within the first two weeks of training, before muscle hypertrophy could have been a factor.

The importance of neural factors in strength training is evident in at least three phenomena: 1) strength increases without proportional increase in muscle cross-sectional area. ${ }^{164}, 2$ ) unilateral limb training, which results in increased strength in both the trained limb and the untrained contralateral limb, particularly if the untrained side is used to maintain balance ${ }^{165}$; and 3) decreased strength output in one limb when both limbs activate simultaneously during the strength task, and this decreased strength output is ameliorated by training and familiarity with the task. ${ }^{166}$ The neural factors hypothesis suggests central and peripheral nervous system involvement in strength output. Strength expression has been proposed to involve a central command from a supraspinal center that is transformed into a sequence of muscle activations (motor program) by the spinal cord or brain stem and then transmitted to the specific muscles. ${ }^{166}$ During a sustained task, such as a strength test, central command or motor program output can be modified by central feedback or afferent somatosensory feedback.

Increased strength may be due to the acquisition of skill in performing the task, which involves the increase in strength or coordination of other fixator muscles necessary for body support during task performance. ${ }^{167}$ In tasks that require precision or when subjects are untrained, practice and training lead to more coordinated contraction of muscular agonists and less antag- onist co-contraction; the final result is greater agonist activation and net force in the intended direction of movement. ${ }^{168}$ The response to strength training is greatest for the specific task trained, at a specific muscle length (limb position or angle), and, generally, at a specific velocity. ${ }^{163}$

Thus, it would appear that task-specific exercise may also be beneficial for learning to maintain postural control (see vestibular and higher cortical/central sections below). For example, strength training can be incorporated into movements that mirror everyday tasks instead of focusing on isolated flexion-extension movements that increase the strength of certain muscle groups. ${ }^{169}$ Could these training methods be directed more specifically toward a more efficient muscle strategy (more coordinated synergists and less agonistantagonist co-contraction)? There is evidence that leg EMG responses to a translational perturbation are less coordinated in older compared with younger adults. ${ }^{48}$ Inappropriate co-contraction of muscle agonists and antagonists can result in joint stiffness and stabilization, which may be counterproductive when additional responses to the perturbation are required. Could more specific fall response strategies requiring rapid motor responses be trained safely by using explosive-type strength training, as suggested by Hakkinen and Hakkinen? ${ }^{108}$ Repeated attempts at contracting rapidly (explosive training) may increase the ability of motor units to fire briefly at high rates. ${ }^{162}$ There is also evidence that with strength training, the weakest older adult subjects may improve the most dramatically at the highest test velocities. ${ }^{170}$ Finally, in young normals, rapid voluntary postural sways that are well-practiced, of a predictable direction, and performed under conditions of postural stability, can be executed as quickly as involuntary postural adjustments to platform perturbations. ${ }^{171}$

Strength training by itself may not be sufficient to improve postural control. Postural control decrements produced by enforced bed rest cannot be avoided by bed-based isotonic or isometric exercise. ${ }^{172}$ Training should thus be conducted in upright or leaning positions, for example, whereby the other integral systems, particularly the vestibular and somatosensory systems, are activated. In young normal subjects, repeated head extension and unipedal stance exercises can reduce the postural sway associated with these two tasks, ${ }^{173}$ suggesting again the importance of practicing specific tasks for a specific outcome.

\section{Vestibular System Training}

In patients with peripheral vestibular deficits, primarily those with positionally provoked findings, vestibular habituation exercise training, particularly when customized for each patient, ${ }^{32,174}$ can reduce dizziness, even in older adults. ${ }^{175}$ Postural control in patients with peripheral vestibular deficits can also be improved with vestibular rehabilitation. Of particular interest is the improvement in equilibrium scores when the platform is sway referenced and vision is occluded (SO5) or when both the platform and visual surround are both sway referenced (SO6). ${ }^{176}$ These are the same 
conditions (SO5 and SO6) in which healthy older adults have poorer scores compared with young adults. ${ }^{28}$ Unfortunately, in relatively healthy older adults completing a vestibular-oriented training program, only limited dynamic posturography changes occur compared with controls, although more striking improvements may occur in unipedal stance. ${ }^{27}$

Nevertheless, vestibular rehabilitation techniques may still provide the basis for establishing balance training programs in some older adults, to include exercises in postural response strategies, adapting the use of visual or somatosensory input, particularly during sensory conflict situations, coordination of eye and head movements and stabilization of gaze, and exploration of the limits of perceived stability. ${ }^{15,25}$

\section{Higher Cortical/Central System Training}

In cases of severe fear of falling, behavioral desensitization and other physical therapies may be effective in reducing fear and facilitating ambulation. ${ }^{177}$ Ideokinetic facilitation, a technique of imagined movement used to change posture and/or neuromuscular patterns, may help improve postural control. ${ }^{178}$ Other types of visual forceplate and therapist-guided postural feedback may decrease asymmetric weight-bearing and improve weight-shifting in hemiplegic patients, but these improved skills may not translate into decreased postural sway or improved gait parameters. ${ }^{142,179}$

Keshner and Cohen ${ }^{66}$ suggest a set of guidelines to assist a patient in planning motor response patterns to improve postural stability. These include information about task demands and verbal feedback regarding the expected and actual postural responses; graded muscle activation of functionally opposed muscles surrounding a specific joint (agonists and antagonists) and at opposite ends of the body (eg, neck and ankle); intensification of a specific sensory input and supplying cognitive input regarding patient responses (ie, feedback); and practicing the task within a structured environment, free of conflicting stimuli. Patients with visual deficits or who have difficulty compensating for unexpected or novel input would benefit initially from a consistent, unchanging environment that provides reliable and predictable feedback to practice correct postural responses. ${ }^{66}$

\section{FUTURE STUDIES OF POSTURAL CONTROL}

Simple screening tests presently give a general impression of how an older adult maintains his or her postural control (see test battery section). However, to understand more fully the mechanisms whereby postural control declines with age and disease or improves with specific training programs, a more quantitative approach appears to be necessary.

For future quantitative studies of postural control in older adults, biomechanical measures (such as Center of Mass, COP, joint angle, and joint torques) may be preferred over EMG measures (such as activation order, latency, and amplitude). ${ }^{8,13}$ The biomechanical parameters provide a more direct measure of postural control during performance of daily activities. In addition, the empirical and theoretical relationships between EMG activity and biomechanical measures are incompletely understood, especially for complex multi-joint movements. EMG activation sequences may not have distinct kinetic or biomechanical correlates, eg, the relationship between integrated EMG amplitude and force output may be non-linear. ${ }^{180}$ Finally, discrete, stereotyped EMG patterns, common in young adults under certain conditions, may not be particularly common in either able-bodied or disabled older adults.

There still may be problems with inferences made from biomechanical measures, as pointed out by Winter. ${ }^{181}$ Foremost is the issue of indeterminacy: for a given series of joint motions, a number of combinations of muscle forces, ie, torque strength patterns, can generate the moments of forces observed. Because the same kinematic pattern might be generated by different motor patterns, analyses must consider how more than one joint affects the moment of forces observed. A list of abnormal movement patterns might then be generated with their associated possible etiologies. This might culminate in a list of possible therapeutic, rehabilitative, preventive, and adaptive measures, as has been done with other functional balance test abnormalities. ${ }^{18}$

\section{CONCLUSIONS}

Appropriate evaluation of postural control in older adults should include sampling the various perturbations of postural control that occur during daily activities, such as in different positions, during position changes, on different support surfaces, and in response to external forces.

Age-related changes in maintenance of postural control may be minimal in quiet stance or with mild perturbations, while changes can be demonstrated more reliably during more severe perturbations of balance. Age-associated changes in certain previous studies may have been due instead to subtle underlying diseases associated with aging.

Appropriate models for postural control in older adults must consider visual, vestibular, somatosensory, and musculoskeletal system function. Of particular importance, and perhaps underemphasized in the past, is how all of these systems are integrated under higher cortical/central influences, particularly regarding influences from cognitive, affective, and behavioral domains.

Age-related and disease-related declines in functioning of these systems put older adults at risk for difficulty in maintaining postural control and, ultimately, falls. Patients with certain diseases manifest certain postural control responses, which can be characterized by laboratory-based postural testing.

Postural control training programs in older adults have thus far not achieved consistently striking gains in balance ability. Specific techniques to improve aspects of strength and muscle function, vestibular function, and higher cortical/central function may be of value in older adult training programs.

The use of quantifiable biomechanical parameters, either with or without associated EMG parameters, may be most useful in future studies of postural control in older adults. 


\section{ACKNOWLEDGMENTS}

The author thanks Albert B. Schultz, PhD, and Neil T. Shepard, PhD, for their thoughtful reviews of this manuscript.

\section{REFERENCES}

1. Tinetti ME, Speechley M, Ginter SF. Risk factors for falls among elderly persons living in the community. N Engl J Med 1988:319:1701-1707.

2. Fernie GR, Gryfe CI, Holliday PJ, et al. The relationship of postural sway in standing to the incidence of falls in geriatric subjects. Age Ageing 1982;11:11-16

3. Ring C, Nayak USL, Isaacs, B. Balance function in elderly people who have and have not fallen. Arch Phys Med Rehabil 1988;69:261-264.

4. Wolfson LI, Whipple R, Amerman P, et al. Stressing the postural response A quantitative method for testing balance. J Am Geriatr Soc 1986;34 845-850.

5. Tinetti ME, Williams TF, Mayewski R. Fall risk index for elderly patients based on number of chronic disabilities. Am J Med 1986;80:429-434.

6. Lipsitz LA, Jonsson PV, Kelley MM, et al. Causes and correlates of recurrent falls in ambulatory frail elderly. J Gerontol 1991;46:M114-121.

7. Lord SR, Clark RD, Webster IW. Physiological factors associated with falls in an elderly population. J Am Geriatr Soc 1991;39:1194-1200.

8. Studenski S, Duncan PW, Chandler J. Postural responses and effector factors in persons with unexplained falls: Results and methodologic issues. J Am Geriatr Soc 1991:39:229-234.

9. Robbins AS, Rubenstein LZ, Josephson KR, et al. Predictors of falls among elderly people: results of two population-based studies. Arch Intern Med 1989;149:1628-1633.

10. Sixt E, Landahl S. Postural disturbances in a 75-year-old population: I Prevalence and functional consequences. Age Ageing 1987;16:393-398.

11. Gerson LW, Jarjoura D, McCord G. Risk of imbalance in elderly people with impaired hearing or vision. Age Ageing 1989;18:31-34.

12. Horak FB. Clinical measurement of postural control in adults. Phys Ther 1987;67:1881-1885.

13. Lee WA. A control systems framework for understanding normal and abnormal posture. Am J Occup Ther 1989;43:291-301

14. McCollum G, Leen TK. Form and exploration of mechanical limits in erect stance. J Motor Behav 1989:21:225-244.

15. Shumway-Cook A, Horak FB. Rehabilitation strategies for patients with vestibular deficits. Neurol Clin 1990;8:441-457.

16. Schultz AB, Alexander NB, Ashton-Miller JA. Biomechanical analyses of rising from a chair. J Biomech 1992;25:1381-1391.

17. Mathias A, Nayak USL, Isaacs B. Balance in elderly patients: The "getup and go" test. Arch Phys Med Rehabil 1986;67:387-389.

18. Tinetti ME. Performance-oriented assessment of mobility problems in elderly patients. J Am Geriatr Soc 1986;34:119-126.

19. Lichtenstein MJ, Burger MC, Shields SL, et al. Comparison of biomechanics platform measures of balance and videotaped measures of gait with a clinical mobility scale in elderly women. J Gerontol 1990;45 M49-54.

20. Berg K, Wood-Dauphinee S, Williams JI, et al. Measuring balance in the elderly: Preliminary development of an instrument. Physiother Can 1989;41:304-311.

21. Duncan PW, Weiner DK, Chandler J, et al. Functional reach: A new clinical measure of balance. J Gerontol 1990;45:M192-197.

22. Winter DA, Patla AE, Frank JS. Assessment of balance control in humans Med Prog Technol 1990;16:31-51.

23. Bohannon RW, Larkin PA, Cook AC, et al. Decrease in timed balance test scores with aging. Phys Ther 1984;64:1067-1070.

24. Alexander NB, Shepard N, Gu MJ, et al. Postural control in young and elderly adults when stance is perturbed: Kinematics. J Gerontol 1992;47:M79-87.

25. Shumway-Cook A, Horak FB. Assessing the influence of sensory interaction on balance. Phys Ther 1986;66:1548-1550.

26. Anacker SL, DiFabio RP. Influence of sensory inputs on standing balance in community-dwelling elders with a recent history of falling. Phys Ther 1992;72:575-584

27. Ledin $\mathrm{T}$, Kronhed $\mathrm{AC}$, Moller $\mathrm{C}$, et al. Effects of balance training in elderly evaluated by clinical tests and dynamic posturography. J Vestib Res 1991;1:129-138.

28. Shepard NT, Schultz A, Alexander NB, et al. Postural control in young and elderly adults when stance is challenged clinical versus laboratory measurements. Ann Oto Rhino Laryngol 1993;102:508-517.

29. Horak FB, Mirka A, Shupert CL. The role of peripheral vestibular disorders in postural dyscontrol in the elderly. In: Woollacott MH, Shum way-Cook A, eds. Development of Posture and Gait Across the Life Span. Columbia, SC: University of South Carolina Press, 1989, pp 253279 .

30. Graybiel A, Fregley AR. A new quantitative ataxia test battery. Acta Otolaryngol 1966;61:292-312.

31. Chandler JM, Duncan PW, Studenski SA. Balance performance on the postural stress test: Comparison of young adults, healthy elderly, and fallers. Phys Ther 1990;70:410-415.
32. Shepard NT, Telian SA, Smith-Wheelock M, et al. Vestibular and balance rehabilitation therapy. Ann Oto Rhinol Laryngol 1993, in press.

33. Black FO, Shupert CL, Peterka RJ, et al. Effects of unilateral loss of vestibular function on the vestibulo-ocular reflex and postural control. Ann Oto Rhinol Laryngol 1989;98:884-889.

34. Berg KO, Maki BE, Williams JI, et al. Clinical and laboratory measures of postural balance in an elderly population. Arch Phys Med Rehabi 1992;73:1073-1080.

35. Ekdahl C, Jarnio GB, Andersson SI. Standing balance in healthy subjects. Scand J Rehabil Med 1989;21:187-195.

36. Hasselkus BR, Shambes GM. Aging and postural sway in women. J Gerontol 1975;30:661-667.

37. Luchies $C W$, Alexander NB, Schultz AB, et al. Stepping responses of young and old adults to postural disturbances: Kinematics. J Am Geriatr Soc 1993, in press.

38. Maki BE, Holliday PJ, Fernie GR. Aging and postural control: a comparison of spontaneous- and induced-sway balance tests. J Am Geriatr Soc 1990;38:1-9.

39. Manchester D, Woollacott $M$, Zederbauer-Hylton $N$, et al. Visual, vestibular and somatosensory contributions to balance control in the older adult. J Gerontol 1989;44:M118-127.

40. Murray MP, Wood AAS, Sepic SB. Normal postural stability and steadiness: Quantitative assessment. J Bone Joint Surg 1975;57:510-516.

41. Ring C, Mathews R, Nayak USL, et al. Visual push: A sensitive measure of dynamic balance in man. Arch Phys Med Rehabil 1988;69:256-260.

42. Ring C, Nayak USL, Isaacs B. The effect of visual deprivation and proprioceptive change on postural sway in healthy adults. J Am Geriatr Soc 1989;37:745-749.

43. Stelmach GE, Phillips J, DiFabio RP, et al. Age, functional postural reflexes and voluntary sway. J Gerontol 1989;44:B100-106.

44. Stelmach GE, Teasdale N, DiFabio RP, et al. Age-related decline in postural control mechanisms. Int J Aging Hum Dev 1989;29:205-223.

45. Straube A, Botzel $K$, Hawken $M$, et al. Postural control in the elderly: Differential effects of visual, vestibular, and somatosensory input. In: Amblard B, Berthoz A, Clarac F, eds. Posture and Gait: Development Adaptation, and Modulation. New York: Elsevier, 1988, pp 105-114.

46. Teasdale N, Stelmach GE, Breunig A. Postural sway characteristics of the elderly under normal and altered visual and support surface conditions. J Gerontol 1991;46:B238-244.

47. Teasdale N, Stelmach GE, Breunig $A$, et al. Age differences in visual sensory integration. Exp Brain Res 1991;85:691-696.

48. Woollacott MH, Shumway-Cook A, Nashner LM. Aging and posture control: Changes in sensory organization and muscular coordination. In J Aging Hum Dev 1986;23:97-114.

49. Diener HC, Bootz F, Dichgans J, et al. Variability of postural "reflexes" in humans. Exp Brain Res 1983;52:423-428.

50. Kirby RL, Price NA, MacLeod DA. The influence of foot position on standing balance. J Biomech 1987;20:423-427.

51. Mauritz KH, Dietz V. Characteristics of postural instability induced by ischemic blocking of leg afferents. Exp Brain Res 1980;38:117-119.

52. Diener HC, Dichgans J, Guschlbauer B, et al. The significance of proprioception on postural stabilization as assessed by ischemia. Brain Res 1984;296:103-109.

53. Nashner LM. Adapting reflexes controlling the human posture. Exp Brain Res 1976;26:59-72.

54. Era P, Heikkinen E. Postural sway during standing and unexpected disturbance of balance in random samples of men of different ages. J Gerontol 1985;40:287-295.

55. Pykko I, Jantti $P$, Aalto $H$. Postural control in elderly subjects. Age Ageing 1990;19:215-221.

56. Briggs RC, Gossman MR, Birch R, et al. Balance performance among noninstitutionalized elderly women. Phys Ther 1989;69:748-756.

57. Diener HC, Dichgans J, Bootz F, et al. Early stabilization of human posture after a sudden disturbance: Influence of rate and amplitude of displacement. Exp Brain Res 1984;56:126-134.

58. Horak FB, Nashner LM. Central programming of postural movements: Adaptation to altered support-surface configurations. J Neurophysiol 1986;35:1369-1381

59. Nashner LM. Fixed patterns of rapid postural responses among leg muscles during stance. Exp Brain Res 1977;30:13-24.

60. Keshner EA, Woollacott MH, Debu B. Neck, trunk, and limb muscle responses during postural perturbations in humans. Exp Brain Res 1988;71:455-466.

61. Allum JHJ, Pfaltz CR. Visual and vestibular contributions to pitch sway stabilization in the ankle muscles of normals and patients with bilateral peripheral vestibular deficits. Exp Brain Res 1985;58:82-94.

62. Allum JHJ, Keshner EA. Vestibular and proprioceptive control of sway stabilization. In: Bles $W$, Brandt $T$, eds. Disorders of Posture and Gait. New York: Elsevier, 1986, pp 19-40.

63. Keshner EA, Allum JHJ, Pfaitz CR. Postural coactivation and adaptation in the sway stabilizing responses of normals and patients with bilateral vestibular deficit. Exp Brain Res 1987;69:77-92.

64. Diener HC, Horak FB, Nashner LM. Influence of stimulus parameters on human postural responses. J Neurophysiol 1988;59:1888-1905.

65. Diener HC, Dichgans J, Guschlbauer B, et al. Role of visual and static vestibular influences on dynamic postural control. Hum Neurobiol 1986:5:105-113. 
66. Keshner EA, Cohen $\mathrm{H}$. Current concepts of the vestibular system reviewed: 1 . The role of the vestibulospinal system in postural control. Am J Occup Ther 1989;43:320-330, 1989.

67. Diener HC, Dichgans J, Guschlbauer B, et al. The coordination of posture and voluntary movement in patients with cerebellar dysfunction. Movement Disord 1992;7:14-22.

68. LLinas $R$, Walton $K$. Vestibular compensation: A distributed property of the central nervous system. In: Asanyma $H$, Wilson VT, eds. Integration in the Nervous System. Tokyo: Igaku-Shoin, 1979, pp 145-166.

69. Keshner EA, Allum JHJ. Plasticity in pitch sway stabilization: normal habituation and compensation for peripheral vestibular deficits. In: Bles W, Brandt T, eds. Disorders of Posture and Gait. New York: Elsevier, 1986, pp 289-314.

70. Larsson L, Grimsby G, Karlsson J. Muscle strength and speed of movement in relation to age and muscle morphology. J Appl Physiol $1979 ; 46: 451-456$

71. Lord SR, Clark RD, Webster IW. Postural stability and associated physiological factors in a population of aged persons. J Gerontol 1991;46: M69-76.

72. Faulkner JA, Brooks SV, Zerba E. Skeletal muscle weakness and fatigue in old age: Underlying mechanisms. Annu Rev Gerontol Geriatr 1990;10:147-166

73. Curcio CA, Buell SJ, Coleman PD. Morphology of the aging central nervous system: Not all downhill. In: Mortimer J, Pirozzolo F, Maletta G, eds. The Aging Motor System. New York: Praeger, 1982, pp 7-35.

74. Schaumberg HH, Spencer PS, Ochoa J. The aging human peripheral nervous system. In: Katzman R, Terry R. eds. The Neurology of Aging. Philadelphia: FA Davis, 1983. pp 111-122

75. Lord SR, Clark RD, Webster IW. Visual acuity and contrast sensitivity in relation to falls in an elderly population. Age Ageing 1991;20:175-181.

76. Nevitt MC, Cummings SR, Kidd S, et al. Risk factors for recurren nonsyncopal falls: A prospective study. JAMA 1989;261:2663-2668.

77. Tobis JS, Reinsch S, Swanson JM, et al. Visual perception dominance of fallers among community-dwelling older adults. J Am Geriatr Soc 1985;33:330-333.

78. Felson DT, Anderson JJ, Hannan MT, et al. Impaired vision and hip fracture: the Framingham study. J Am Geriatr Soc 1989;37:495-500.

79. Campbell A], Borrie MJ, Spears GF. Risk factors for falls in a community based prospective study of people 70 years and older. J Gerontol 1989;44:M112-117.

80. Amblard B, Cremieux J, Marchand AR, et al. Lateral orientation and stabilization of human stance: Static versus dynamic cues. Exp Brain Res 1985;61:21-37

81. Nashner LM, Berthoz A. Visual contribution to rapid motor responses during postural control. Brain Res 1978;150:403-407.

82. Sekuler R, Hutman LP, Owsley CJ. Human aging and spatial vision. Science 1980;209:1255-1256.

83. Carter $\mathrm{JH}$. The effects of aging on selected visual functions: Color vision, glare sensitivity, field of vision, and accommodation. In: Sekuler R, Kline D, Dismukes K, eds. Aging and Human Visual Function. New York: Alan R. Liss, 1982, pp 121-130.

84. Pitts DG. The effects of aging on selected visual functions: dark adaptation, visual acuity, stereopsis, and brightness contrast. In: Sekuler R, Kline D, Dismukes K, eds. Aging and Human Visual Function. New York: Alan R. Liss, 1982, pp 131-159.

85. Owen DH. Maintaining posture and avoiding tripping. Optical information for detecting and controlling orientation and locomotion. Clin Geriatr Med 1985; 1:581-599.

86. Simoneau GG, Leibowitz HW, Ulbrecht JS, et al. The effects of visual factors and head orientation on postural steadiness in women 55 to 70 years of age. J Gerontol 1990;47:M151-M158

87. Pykko I, Aalto A, Hytonen M, et al. Effect of age on postural control. In Amblard B, Berthoz A, Clarac F, eds. Posture and Gait: Development, Adaptation, and Modulation. New York: Elsevier, 1988, pp 95-104.

88. Kokmen E, Bossemeyer RW, Williams WJ. Quantitative evaluation of joint motion sensation in an aging population. J Gerontol 1978;33: 62-67.

89. Skinner HB, Barrack RL, Cook SD. Age-related decline in proprioception. Clin Orthop Rel Res 1984;184:208-211.

90. Thombury JM, Mistretta CM. Tactile sensitivity as a function of age. J Gerontol 1981;36:34-39.

91. Mauritz KH, Dietz V, Haller M. Balancing as a clinical test in the differential diagnosis of sensory disorders. J Neurol Neurosurg Psychiatr 1980;43:407-412.

92. Magnusson $M$, Enbom $H$, Johansson $R$, et al. Significance of pressor input from the human feet in lateral postural control. Acta Otolaryngol 1990;100:321-327.

93. Rosenhall U. Degenerative patterns in the aging human vestibular neuroepithelia. Acta Otolaryngol 1973;76:208-220.

94. Peterka RJ, Black FO, Schoenhoff MB. Age-related changes in human vestibulo-ocular reflexes: Sinusoidal rotation and caloric tests. J Vestib Res 1990:1:49-59.

95. Pozzo T, Berthoz A, Lefort L. Head stabilization during various locomotor tasks in humans. I. Normal subjects. Exp Brain Res 1990;82:97-106.

96. Viviani $P$, Berthoz A. Dynamics of head-neck systems in response to small perturbations: Analysis and modeling in the frequency domain. Biol Cybern 1975;19:19-37.
97. Wyke B. Cervical articular contributions to posture and gait: Their relation o senile disequilibrium. Age Ageing 1979;8:251-258.

98. Richmond FJR, Abrahams VC. What are the proprioceptors of the neck? In: Granit R, Pompeiano O, eds. Progress in Brain Research Reflex Control of Posture and Movement Amsterdam: Elsevier, 1979, pp 245-254.

99. Diener HC, Dichgans J. On the role of vestibular, visual, and somatosen sory information for dynamic postural control in humans. In: Pompeiano O, Allum JHJ, eds. Progress in Brain Research. Vol. 76, New York: Elsevier, 1988, pp 253-262.

100. Jackson RT, Epstein CM. Effects of head extension on equilibrium in normal subjects. Ann Otol Rhinol Laryngol 1991;100:63-67.

101. Barin K, Seitz CM, Welling DB. Effects of head orientation on the diagnostic sensitivity of posturography in patients with compensated unilateral lesions. Otolaryngol Head Neck Surg 1992;106:355-362.

102. Nashner LM, Black FO, Wall C. Adaptation to altered support and visual conditions during stance: Patients with vestibular deficits. J Neuroscience $1982 ; 2: 536-544$.

103. Bronstein AM. Suppression of visually evoked responses. Exp Brain Res 1986;63:655-658.

104. Whipple RH, Wolfson LI, Amerman PM. The relationship of knee and ankle weakness to falls in nursing home residents: An isokinetic study. J Am Geriatr Soc 1987;35:13-20.

105. Vandervoort AA, Chesworth BM, Cunningham DA, et al. Age and sex effects on mobility of the human ankle. J Gerontol 1992;47:M17-21.

106. Makrides L, Heigenhauser GJF, McCartney N, et al. Maximal short term exercise capacity in healthy subjects aged 15-70 years. Clin Sci 1985;69:197-205

107. Bassey EJ, Fiatarone MA, O'Neill EF, et al. Leg extensor power and functional performance in very old men and women. Clin Sci 1992;82:321-327.

108. Hakkinen $K$, Hakkinen A. Muscle cross-sectional area force production and relaxation characteristics in women at different ages. Eur J Appl Physiol 1991;62:410-414

109. Such $\mathrm{CH}$, Unsworth A, Wright V, et al. Quantitative study of stiffness in the knee joint. Ann Rheum Dis 1975;34:286-291.

110. (Deleted in press)

111. Buchner DM, de Lateur BJ. The importance of skeletal muscle strength to physical function in older adults. Ann Behav Med 1991;13:91-98.

112. Iverson BD, Gossman MR, Shaddeau $\mathrm{SA}$, et al. Balance performance, force production, and activity levels in noninstitutionalized men 60-90 years of age. Phys Ther 1990;70:348-355.

113. Salthouse TA, Somberg BL. Time-accuracy relationships in young and old adults. J Gerontol 1982;37:349-353.

114. Baylor AM. Plasticity and exercise effects on aging motor function. In Woollacott MH, Shumway-Cook A, eds. Development of Posture and Gait Across the Life Span. Columbia, SC: University of South Carolina Press, 1989, pp 202-225.

115. Rabbit $P$. How old and young subjects monitor and control responses for accuracy and speed. Br J Psychol 1979;70:305-311.

116. Stelmach GE, Worringham CJ. Sensorimotor deficits related to postural stability. Implications for falling in the elderly. Clin Geriatr Med 1985;1:679-694.

117. Clarkson PM. The effect of age and activity level on simple and choice fractionated response time. Eur J Appl Physiol 1978;40:17-25.

118. (Deleted in press)

119. Botwinick J. Disinclination to venture response versus cautiousness in responding: age differences. J Genet Psych 1969;115:55-62.

120. Okun MA. Adult age and cautiousness in decision: $A$ review of the literature. Hum Dev 1976;19:220-233

121. Tanaka $Y$, Takeya $T$, Ohno $Y$, et al. The influence of psychological stress on fine body movement. Agressologie 1979;20:165-166.

122. Hallam RS, Hinchcliffe R. Emotional stability: Its relationship to confidence in maintaining balance. J Psychosoma Res 1991;35:421-430.

123. Jacob RG. Panic disorder and the vestibular system. Psychiatr Clin N Am 1988;11:361-374

124. Tinetti ME, Richman $D$, Powell $L$. Falls efficacy as a measure of fear of falling. J Gerontol 1990;45:P239-243.

125. Maki BE, Holliday PJ, Topper AK. Fear of falling and postural performance in the elderly. J Gerontol 1991;46:M123-131.

126. Greenwood R, Hopkins A. Muscle responses during sudden falls in man J Physiol 1976:254:507-518.

127. Woollacott MH, von Hosten $\mathrm{C}$, Rosblad B. Relation between muscle response onset and body segmental movements during postural perturbations in humans. Exp Brain Res 1988;72:593-604.

128. Badke MB, Duncan PW, DiFabio RP. Influences of prior knowledge on automatic and voluntary postural adjustments in healthy and hemiplegic subjects. Phys Ther 1987;67:1495-1500.

129. Cordo PJ, Nashner LM. Properties of postural adjustments associated with rapid arm movements. J Neurophysiol 1982;47:287-302.

130. Horak FB, Esselman P, Anderson ME, et al. The effects of movement velocity, mass displaced, and task certainty on associated postural adjustments made by normal and hemiplegic individuals. J Neurol Neurosurg Psychiatr 1984;47:1020-1028.

131. Rogers MW, Kukulka CG, Soderberg GL. Age-related changes in postural responses preceding rapid self-paced and reaction time movements. J Gerontol 1992;47:M159-M165

132. Inglin B, Woollacott M. Age-related changes in anticipatory postural 
adjustments associated with arm movements. J Gerontol 1988;43: M105-113.

133. Woollacott MH, Manchester DL. Anticipatory postural adjustments in older adults: Are changes in response characteristics due to changes in strategy? J Gerontol 1993;48:M64-M70

134. Stelmach GE, Populin L, Muller F. Postural muscle onset and voluntary movement in the elderly. Neurosci Lett 1990;117:188-193.

135. Horak FB, Diener HC, Nashner LM. Influence of central set on human postural responses. J Neurophysiol 1989b;62:841-853.

136. Geurts $\mathrm{ACH}$, Mulder $\mathrm{T}$, Nienhuis $\mathrm{B}$, et al. Dual-task assessment of reorganization of postural control in persons with lower limb amputation. Arch Phys Med Rehabil 1991;72:1059-64.

137. Guitton D, Keamey RE, Wereley N, et al. Visual, vestibular, and voluntary contributions to human head stabilization. Exp Brain Res 1986;64:59-69.

138. Bienhold $H$, Abeln $W$, Flohr. Drug effects on vestibular compensation. In: Flohr $\mathrm{H}$, Precht $\mathrm{W}$ eds. Lesion-induced Neuronal Plasticity in Sensorimotor Systems. New York: Springer-Verlag, 1981, pp 265-273.

139. Badke $M B$, Duncan $P W$. Patterns of rapid motor responses during postural adjustments when standing in healthy and hemiplegic patients. Phys Ther 1983;63:13-20.

140. Difabio RP. Lower extremity antagonist muscle response following standing perturbation in subjects with cerebrovascular disease. Brain Res 1987;406:43-51

141. DiFabio RP, Badke MB, McEvoy A, et al. Kinematic properties of voluntary postural sway in patients with unilateral primary hemispheric lesions. Brain Res 1990;513:248-254.

142. Shumway-Cook A, Anson D, Haller S. Postural sway biofeedback: Its effect on reestablishing stance stability in hemiplegic patients. Arch Phys Med Rehabil 1988:69:395-400.

143. Diener HC, Dichgans J. Pathophysiology of posture. In: Amblard B, Berthoz A, Clarac F, eds. Posture and Gait: Development, Adaptation, and Modulation. New York: Elsevier, 1988, pp 229-235.

144. Beckley DJ, Bloem BR, van Dijk JG, et al. Electrophysiological correlates of postural instability in Parkinson's disease. Electroencephalogr Clin Neuropsychol 1991;81:263-268.

145. Dietz V, Berger W, Horstmann GA. Posture in Parkinson's disease: Impairment of reflexes and programming. Ann Neurol 1988;24:660-669.

146. Rogers MW, Kukulka CG, Soderberg GL. Postural adjustments preceding rapid arm movements in Parkinsonian subjects. Neurosci Lett 1987;75:246-251.

147. Traub MM, Rothwell JC, Marsden CD. Anticipatory postural reflexes in Parkinson's disease and other akinetic-rigid syndromes and in cerebellar ataxia. Brain 1980;103:393-412

148. Fernie GF, Holliday PJ. Postural sway in amputees and normal subjects J Bone Joint Surg 1978;60:895-898.

149. Isakov $E$, Mizrachi $J$, Ring $H$, et al. Standing sway and weight-bearing distribution in people with below-knee amputations. Arch Phys Med Rehabil 1992;73:174-178.

150. Geurts ACH, Mulder T, Nienhuis B, et al. Postural reorganization following lower limb amputation. Scand J Rehabil Med 1992;24:83-90.

151. Lichtenstein MJ. Shields SL, Shiavi RG, et al. Clinical determinants of biomechanics platform measures of balance in aged women. J Am Geriatr Soc 1988;36:996-1002.

152. Jonsson PV, Lipsitz LA, Kelley $M$, et al. Hypotensive responses to common daily activities in institutionalized elderly: A potential risk for recurrent falls. Arch Intern Med 1990;150:1518-1524.

153. Robin DW, Hasan SS, Lichtenstein MJ, et al. Dose-related effect of triazolam on postural sway. Clin Pharmacol Ther 1991;49:581-588.

154. Buchner DM, Beresford SAA, Larson EB, et al. Effects of physical activity on health status in older adults. II: Intervention studies. Annu Rev Public Health 1992;13:469-488.

155. Lichtenstein MJ, Shields SL, Shiavi RG, et al. Exercise and balance in aged women: A pilot clinical controlled trial. Arch Phys Med Rehabil $1989 ; 70: 138-143$.
156. Hopkins DR, Murrah B, Hoeger WWK, et al. Effect of low-impact aerobic dance on the functional fitness of elderly women. Gerontologist 1990;30:189-192.

157. Crilly RG, Willems DA, Trenholm KJ, et al. Effect of exercise on postural sway. J Gerontol 1989;35:137-143.

158. Stones MJ, Kozma A. Balance and age in the sighted and blind. Arch Phys Med Rehabil 1987;68:85-89.

159. Fiatarone MA, Marks EC, Ryan DT, et al. High intensity strength training in nonagenarians. JAMA 1990;263:3029-3034

160. Moritani T, DeVries HA. Neural factors versus hypertrophy in the time course of muscle strength gain. Am J Phys Med 1979;58:115-130.

161. Moritani T, DeVries HA. Potential for gross muscle hypertrophy in older men. J Gerontol 1980;35:672-682.

162. Sale DG. Influence of exercise and training on motor unit activation. Exerc Sport Sci Rev 1987:15:95-151.

163. Jones DA, Rutherford OM, Parker DF. Physiological changes in skeletal muscle as a result of strength training. Q J Exp Physiol 1989;74:233-256.

164. Jones DA, Rutherford OM. Human muscle strength training: The effects of three different regimes and the nature of the resultant changes. I Physiol 1987;391:1-11.

165. Rasch PJ, Morehouse LE. Effect of static and dynamic exercises on muscular strength and hypertrophy. J Appl Physiol 1957;11:29-34.

166. Enoka RM. Muscle strength and its development. Sports Med 1988;6:146-168.

167. Rutherford $O M$, Jones DA. The role of learning and coordination in strength training. Eur J Appl Physiol 1986;55:100-105.

168. Sale DG. Neural adaptation to resistance training. Med Sci Sports Exerc 1988;20:S135-S145.

169. Rutherford OM, Greig CA, Sargeant AJ, et al. Strength training and power output: transference effects in the human quadriceps muscle. I Sports Sci 1986;4:101-107.

170. Aniansson A, Ljungberg $P$, Rundgren A, Wetterqvist W. Effect of training programme for pensioners on condition and muscular strength. Arch Gerontol Geriatr 1984;3:229-241.

171. Nashner LM, Cordo PJ. Relation of automatic postural responses and reaction-time voluntary movements of human leg muscles. Exp Brain Res 1981;43:395-405.

172. Haines RF. Effect of bed rest and exercise on body balance. J Appl Physiol 1974;36:323-327.

173. Brandt T, Buchele W, Krafozyk S. Training effects on experimental postural instability: A model for clinical ataxia therapy. In: Bles W, Brand T, eds. Disorders of Posture and Gait. New York: Elsevier, 1986, pp 353365

174. Telian SA, Shepard NT, Smith-Wheelock M, et al. Habituation therapy for chronic vestibular dysfunction: Preliminary results. Otolaryngol Head Neck Surg 1990;103:89-95.

175. Norre ME, Beckers A. Benign paroxysmal positional vertigo in the elderly Treatment by habituation exercises. J Am Geriatr Soc 1988;36:425-429.

176. Horak FB, Jones-Rycewicz C, Black FO, et al. Effects of vestibular rehabilitation on dizziness and imbalance. Otolaryngol Head Neck Surg 1992;106:175-180.

177. Bhala RP, O'Donnell J, Thoppil E. Ptophobia: Phobic fear of falling and its clinical management. Phys Ther 1982;62:187-190.

178. Fansler CL, Poff CL, Shepard KF. Effects of mental practice on balance in elderly women. Phys Ther 1985:65:1332-1338.

179. Winstein C, Gardner ER, McNeal DR, et al. Standing balance training effect on balance and locomotion in hemiparetic adults. Arch Phys Med Rehabil 1989;70:755-762.

180. Bigland-Ritchie B. EMG/force relations and fatigue of human voluntary contractions. Exerc Sport Sci Rev 1981;9:75-117.

181. Winter DA. Concerning the scientific basis for the diagnosis of patholog ical gait and for rehabilitation protocols. Physiother Can 1985;37: 245-252. 